\title{
AN UPPER BOUND OF A DERIVATIVE FOR SOME CLASS OF POLYNOMIALS
}

\section{KEAITSUdA MANEERUK NAKPRASIT AND JiRAPHORN SOMSUWAN}

Abstract. In [S. Kumar and R. Lal, Generalizations of some polynomial inequalities, Int. Electron. J. Pure Appl. Math., 3, 2 (2011), 111-117.], Kumar and Lal provided an upper bound of a derivative for polynomial degree $n$ having some of zeros at the origin and rest of zeros lying on or outside the boundary of a prescribed disk. In this paper, we present an upper bound of a derivative for polynomials $p(z)=\left(z-z_{m}\right)^{t_{m}}\left(z-z_{m-1}\right)^{t_{m-1}} \cdots\left(z-z_{0}\right)^{t_{0}}\left(a_{0}+\sum_{v=\mu}^{n-\left(t_{m}+\cdots+t_{0}\right)} a_{v} z^{v}\right)$ of degree $n$ having zeros $z_{0}, \ldots, z_{m}$ with $\left|z_{j}\right|<1$ for $0 \leqslant j \leqslant m$ and the remaining $n-\left(t_{m}+\cdots+t_{0}\right)$ zeros are outside $\{z:|z|<k\}$ where $k \geqslant 1$.

Mathematics subject classification (2010): 30A10, 30C10, 30C15. Keywords and phrases: Polynomial, derivative, inequality.

\section{REFERENCES}

[1] A. AzIZ And Q. M. Dawood, Inequalities for a polynomial and its derivative, J. Approx. Theory, 54 (1988), 306-313.

[2] S. BERnstein, Lecons sur les Proprietes extremales et la meilleure approximation des fonctions analytiques d'une variable réelle, Gauthier Villars, Paris, 1926.

[3] T. N. Chan And M. A. Malik, On Erdös-Lax theorem, Proc. Indian Acad. Sci. Math. Sci., 92, 3 (1983), 191-193.

[4] K. K. DEWAn And S. Hans, On extremal properties for the derivative of polynomials, Math. Balkanica, 23, Fasc. 1-2 (2009), 27-35.

[5] N. K. Govil, On a theorem of S. Bernstein, J. Math. Phys. Sci., 14, 2 (1980), 183-187.

[6] N. K. GoviL, Some inequalities for derivatives of polynomials, J. Approx. Theory, 66 (1991), 29-35.

[7] S. KumAR AND R. LAL, Generalizations of some polynomial inequalities, Int. Electron. J. Pure Appl. Math., 3, 2 (2011), 111-117.

[8] P. D. LAX, Proof of a conjecture of P. Erdös on the derivatives of a polynomial, Bull. Amer. Math. Soc., 50 (1944), 509-513.

[9] M. A. MaliK, On the derivative of a polynomial, J. Lond. Math. Soc., 2, 1 (1969), 57-60.

[10] M. S. PUKhtA, Extremal problems for polynomials and on location of zeros of polynomials, $\mathrm{Ph} . \mathrm{D}$. Thesis, Jamia Millia Islamia, New Delhi, 1995. 